\title{
On the Origin and Possible Modification of Hurricanes
}

\author{
By \\ Herbert Riehl
}

\author{
Technical Paper No. 48 \\ Department of Atmospheric Science \\ Colorado State University \\ Fort Collins, Colorado
}

\section{Department of Atmospheric Science}


Reprinted from Science, September 13, 1963, Vol. 141, No. 3585, pages 1001-1010

Copyright (C) 1963 by the American Association for the Advancement of Science

\section{On the Origin and Possible Modification of Hurricanes}

Herbert Riehl
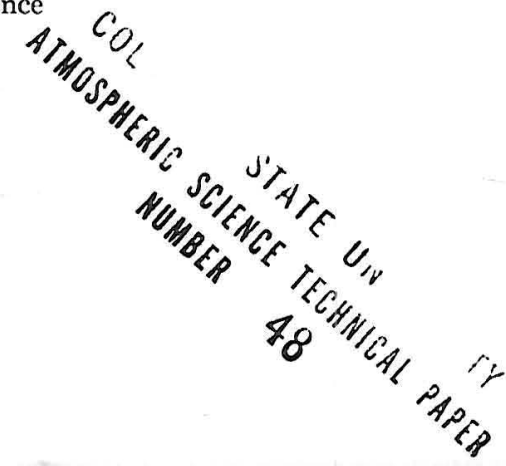


\section{On the Origin and Possible Modification of Hurricanes}

\author{
Herbert Riehl
}

From the scientist's viewpoint, hurricanes or typhoons have been a tempting and, at the same time, unsatisfactory object of investigation: tempting, because tropical revolving storms give the appearance, deceptive perhaps, of being more understandable than their counterparts outside the tropics, the cyclones of middle and high latitudes; unsatisfactory, because these storms exist mainly over the oceans, hence have been very difficult to measure with ground-based observational equipment.

For centuries it has been known that hurricanes develop only over water, though there have been instances of abortive formation over land, for example over the southern United States and over West Africa. The outstanding characteristic of a hurricane is the concentrated core of high winds, with maximum velocities often exceeding 150 kilometers per hour at a distance of, roughly, only 20 kilometers from the calm center, called the "eye." Heavy cloudiness and precipitation accompany the extreme winds.

Faced with this impressive evidence, observers concluded that latent heat of condensation released to the atmosphere in the heavy clouds surrounding the eye furnishes the energy for starting and maintaining hurricanes. Further, they thought that hurricanes developed

The author is head of the department of atmospheric science at Colorado State University, Fort Collins. winds a wavelike appearance (Fig. 1). With this information we can locate foci of potential hurricane danger on every day and can effectively discard the random hypothesis.

The problem of the rarity of hurricane formation, though narrowed, remains with us. At most, 10 percent of Dunn's centers of pressure fall intensify to hurricane strength during the hurricane season, though there is great variation in different years. In 1962, it seemed almost impossible for a hurricane to get going, whereas in 1950 almost every impulse became a storm, from the middle of August on to October. Even so, the total number of hurricanes is never large. In a "good" year, perhaps 50 cyclones of hurricane intensity form in the Northern Hemisphere, whereas 20 to 30 cyclones occur almost every day outside the tropics in the winter season.

This is a strange fact, especially since, among large-scale atmospheric disturbances, the hurricane most closely resembles a simple heat engine. Some of the salient facts are shown in Fig. 2. Air approaches a hurricane center mainly near the ocean surface and then converges laterally and rises, producing a heavy cloud mass over great depth. Outflow occurs at altitudes from about 9000 to 15,000 meters $(30,000$ to 50,000 feet). A broad "canopy" of cirrus cloud is formed by the outflow. The release of energy is obtained through this vertical circulation, because the ascending air is warm relative to the air in the outskirts.

The surface inflow approaches the core along converging spiral trajectories, with strongest convergence to the right of the direction of center propagation. Because of the intense wind stress upon the water, the inflowing mass loses absolute angular momentum about the hurricane axis until it leaves the surface. Hence, in the outflow layer the cyclonic circulation is much weaker than it is at low altitudes, and the direction of circulation changes quickly to anticyclonic as the air current moves o'itward (3). 


\section{Thermal Constraint on}

\section{Hurricane Formation}

The foregoing picture of the mature hurricane is simple and logical; yet it is very difficult for such a circulation to become established. I shall now examine an unusual and, until recently, unexpected fact which, probably, is mainly responsible for the scarcity of hurricanes.

The tropical storm, like all atmospheric disturbances, depends on horizontal differences of temperature for its formation and maintenance. In middle latitudes. substantial temperature gradients exist most of the time. On occasion, these gradients are as high as $20^{\circ} \mathrm{C}$ in 300 kilometers and even higher in the midule of the troposphere (the middle on the basis of weight at a height of 5 to $6 \mathrm{~km}$ ). In the tropics such thermal contrasts never occur as a basic property; there, at their strongest, temperature gradients are lower by an order of magnitude. Yet there must be substantial differences in temperature between the inside and the outside of a hurricane to account for the observed low barometric pressures at the surface and the associated high winds (Fig. 3). It follows that the temperature field observed in hurricanes must be generated along with the storm. In Fig. 3 the curves for moderate and severe hurricanes show the ascent path of air in the thick cloud surrounding the eye of the hurricane, near the radius of strongest wind. This ascending air is warmer in the severe storm than in the moderate storm, and the ascending air in the moderate storm is, in turn, warmer than the mean tropical atmosphere.

Success in understanding hurricane development rests on ability to specify the mechanisms that lead, first, to establishment of the ascent path for the moderate storm and then perhaps also to the severe ascent path for the hurricane.

In a recent article in Science (4) I showed that the atmosphere has a minimum heat content at middle elevations throughout the tropical belt, even in the heart of the equatorial zone (Fig. 4). For an explanation of the observed structure of the tropical atmosphere, one must postulate that a substantial air mass rises in narrow chimneys or "hot towers" along the path marked "undilute ascent" in Fig. 4; that is, the air rising in the chimneys does not mix with the surrounding air. The hurricane ascents of Fig. 3 are also undilute

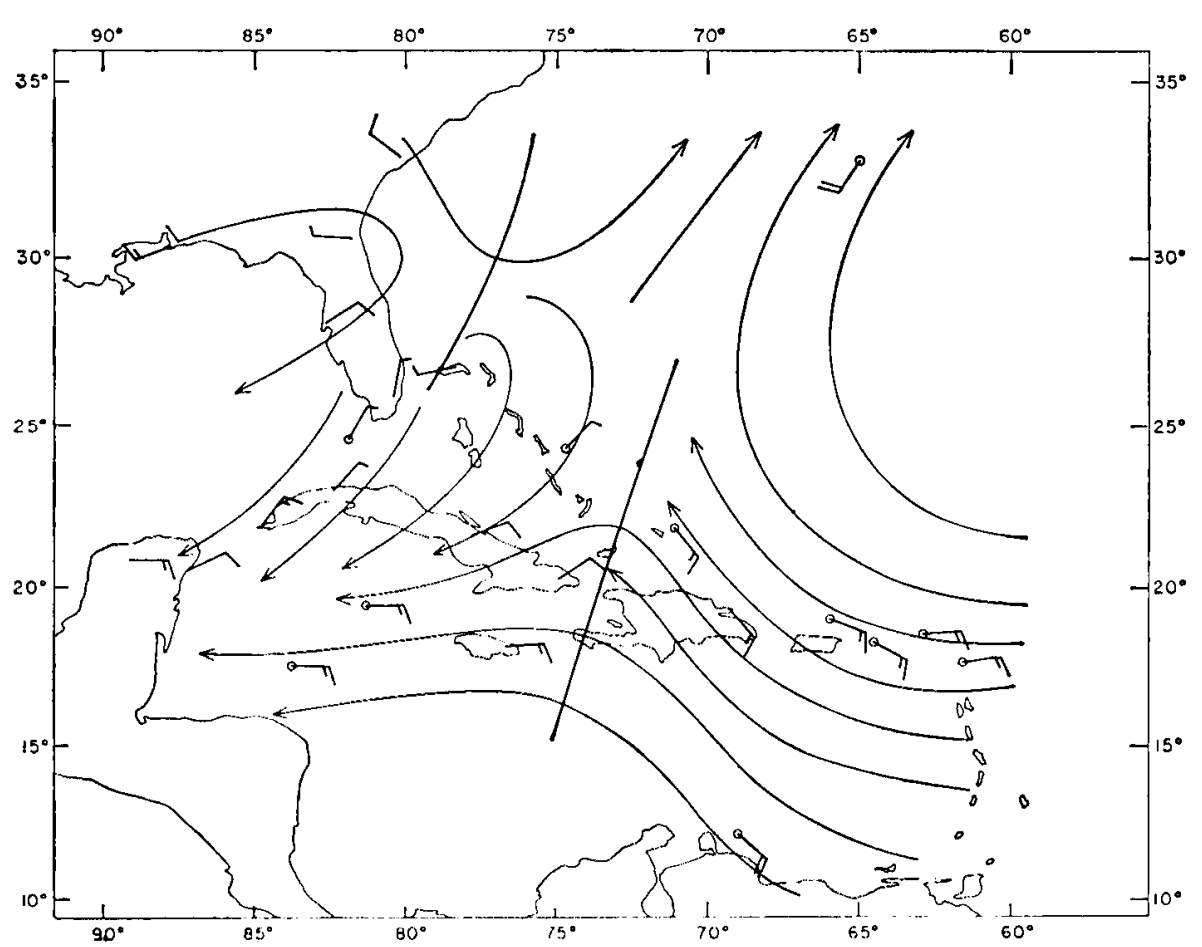

Fig. 1. Streamlines at pressure of 850 millibars (altitude of about $1500 \mathrm{~m}$ ) for the Caribbean on 23 August 1958,0000 Greenwich Mean Time. The solid line extending from the northeast to the southwest through Windward Passage between Cuba and Hispaniola is the wave trough in easterlies that has moved into the area from the east. Hurricane Daisy developed within 2 days. ascents. In the hurricane, the core of heavy rain clouds surrounding the eye must assume the characteristic structure of undilute ascent, at least to a first approximation. Such ascent creates the special "air mass" required for a hurricane to exist. This view is supported by findings of research aircraft missions at altitudes of about 10,700 meters $(35,000 \mathrm{ft})$, where pressures are around 250 millibars: The warmest temperatures coincide with the ring of heavy convection, as seen by radar (Fig. 5).

We cannot say with certainty how temperature fields like those shown in Fig. 5 are established. Certainly we cannot assume that undilute ascent is an initial condition. All evidence indicates that hurricanes are born in an atmosphere where the initial properties are well represented by the curve shown in Fig. 4 for the trade winds or that for the equatorial zone. In areas of disturbed weather with slight fall in pressure (see Fig. 1), air masses converge horizontally up to heights equivalent to pressures of 500 to 400 millibars, importing air with relatively low heat content from the middle troposphere to the central parts of the disturbance $(5,6)$. Figure 6 illustrates the effect of this convergence on the distribution of temperature, with height, for a simple case-the case where the mean tropical atmosphere given in Fig. 3 is lifted a distance equivalent to a difference in pressure of 50 millibars. Since this air initially is unsaturated, it will at first cool during expansion without any modification from release of latent heat; such ascent leads to considerable cooling (Fig. 6, curve at far left). Let us now assume that cloud towers also build upward from the vicinity of the ocean surface and that, after some time, the atmosphere consists of a mixture of air represented by the two outer curves of Fig. 6 . Three choices of mixing rate are shown. From experience we find that soundings show that cooling predominates; only occasionally do we observe net warming of a convective area relative to the surrounding air, as represented by the mean tropical atmosphere.

At this point the reader may well sit back in bewilderment. Research workers in tropical meteorology all were greatly surprised when the existence of the cold core first came to light, just as we were taken aback when ( $\sec 4$ ) 

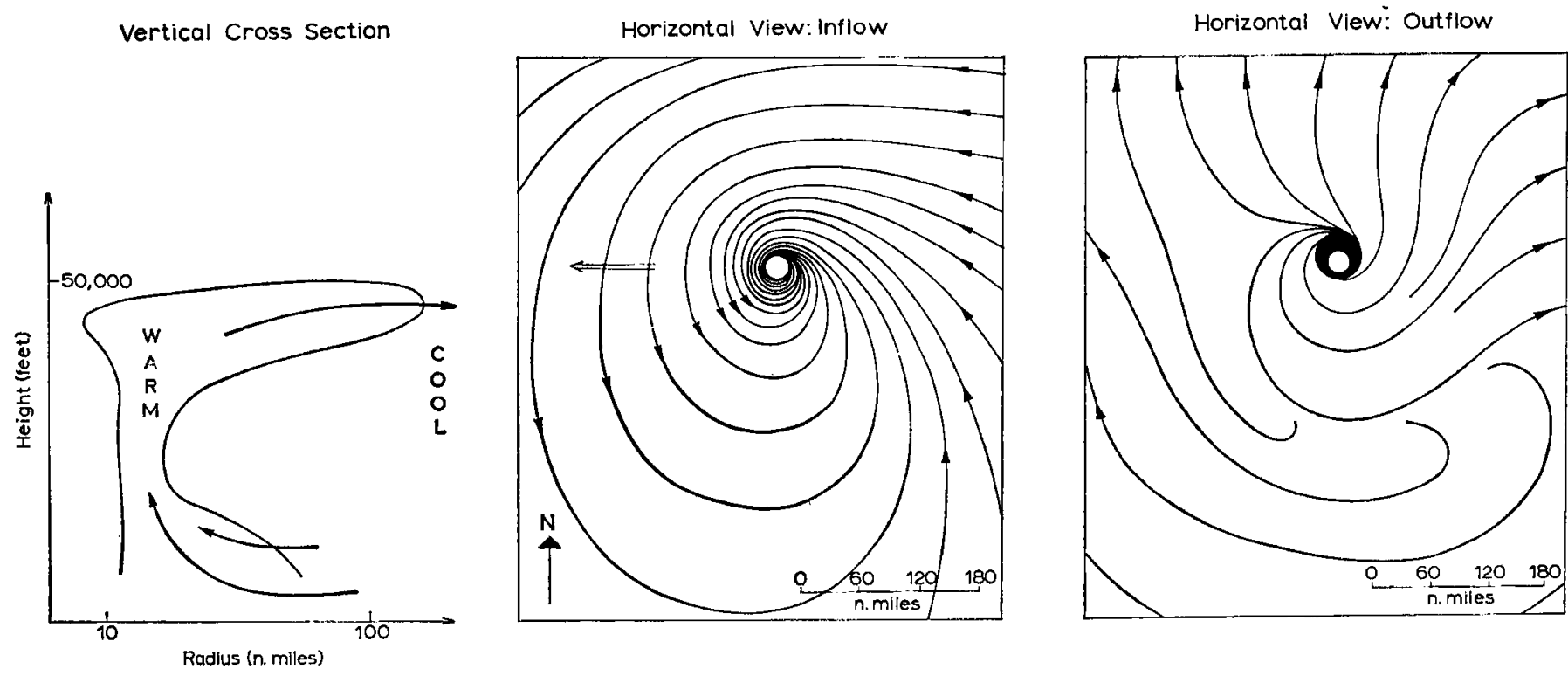

Fig. 2. (Left) Vertical circulation through a hurricane, outline of the main cloud mass, and temperature distribution. (Middle) Streamlines at a height of 300 meters in hurricane Donna southeast of Florida in September 1960. The open arrow indicates the direction of hurricane motion. (Right) Streamlines at a height of 13,700 meters in hurricane Donna.
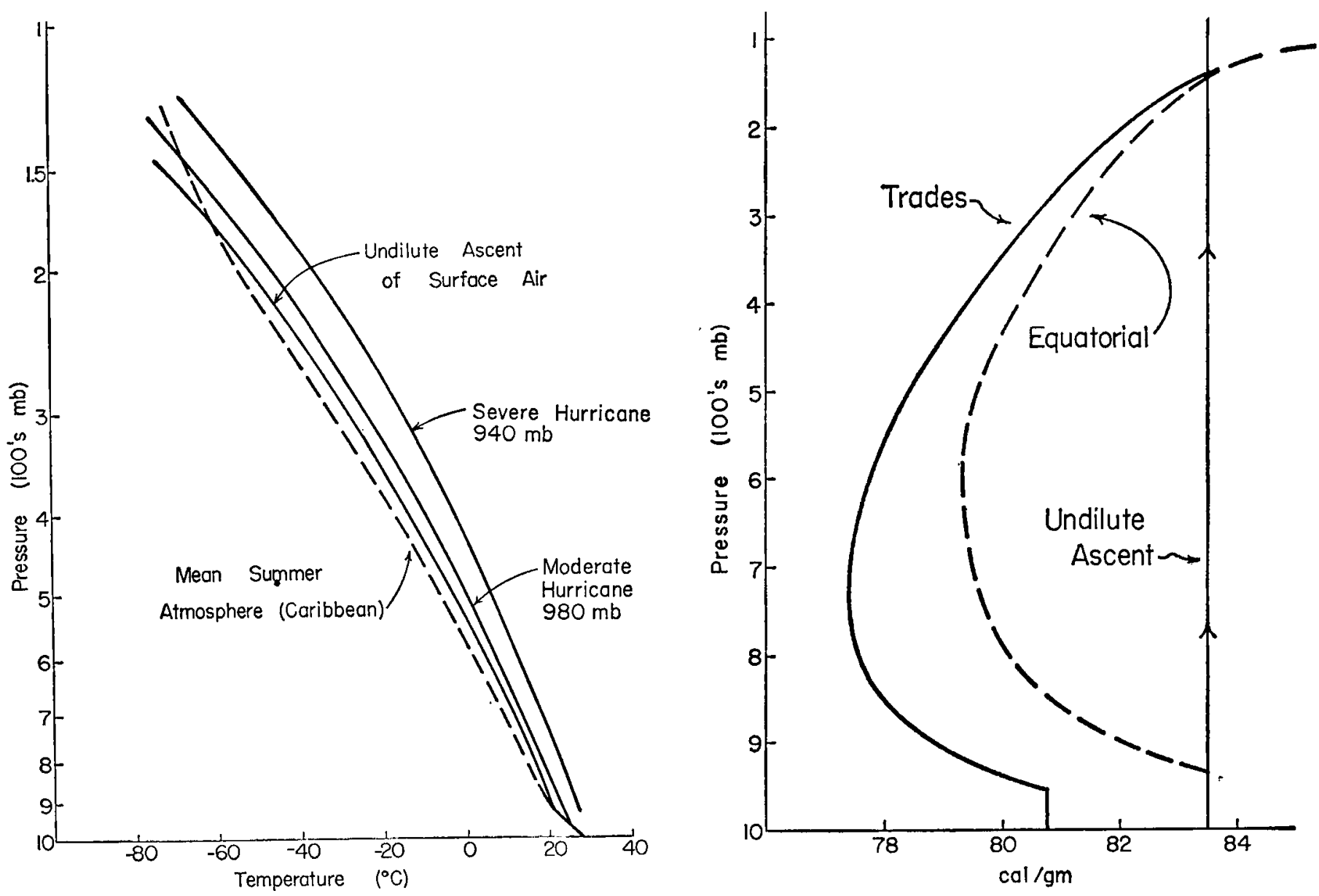

Fig. 3 (left). Temperature (in degrees Celsius) plotted against the logarithm of pressure (essentially, against height). (Dashed line) Structure observed in the mean atmosphere from balloon soundings over the Caribbean in summer. (Solid lines) Structure obtained for an undilute ascent of trade-wind air, and structures required within a moderate and a severe hurricane in the heavy cloud mass around the eye of a hurricane. Fig. 4 (right). Total energy content of the atmosphere (in heat units) as a function of pressure (on a linear scale) for the trade winds, for the equatorial zone, and for the case of undilute ascent of surface air. [Riehl (4)] 
we could no longer evade the fact that the equatorial atmosphere is structured, in the mean, as depicted in Fig. 4. Here we have a tropical disturbance with heavy release of latent heat and with precipitation measured in centimeters per day-even 30 centimeters ( 12 inches) in 24 hours is not too uncommon. Yet the disturbed area is colder and denser than the surrounding atmosphere, and no one has yet shown a way to obtain useful work from the enormous release of latent heat.

Evidently one cannot assume that condensation heating will lead to a build-up of wind energy without prior arrangement of necessary mechanical links, any more than one can assume that a coal or oil fire will yield useful work outside the confines of a properly constructed engine. In the case of cold-core tropical disturbances it is actually necessary to postulate that the surrounding atmosphere does work to keep the disturbance going. This type of observation-which no one did or could predict-makes the field of tropical meteorology a good deal more complicated than meteorologists had supposed it to be.

\section{National Hurricane Research Project}

For the generation of a hurricane, a warm rather than a cold rain area is needed. Therefore we must think of means by which the cold-core disturbance can change and become warm, or we must seek out the occasional rain areas which, at the beginning of our examination, already have a warm core. In any event, it would be most helpful if we could obtain observations that spell out the history of cases when hurricanes started to form and reveal whether a hurricane then did or did not materialize. In this respect very welcome assistance was rendered by a hurricane 9 years ago.

I.ate at night on 30 August 1954, hurricane Carol (7), after moving very slowly off the southeastern coast of the United States, suddenly accelerated and struck New England by way of Long lsland during the morning of 31 August. This visitation, not greatly welcomed by those in the path of the storm, had a marked impact on the tempo of advance in hurricane research. The United States Congress looked into the matter and decided to

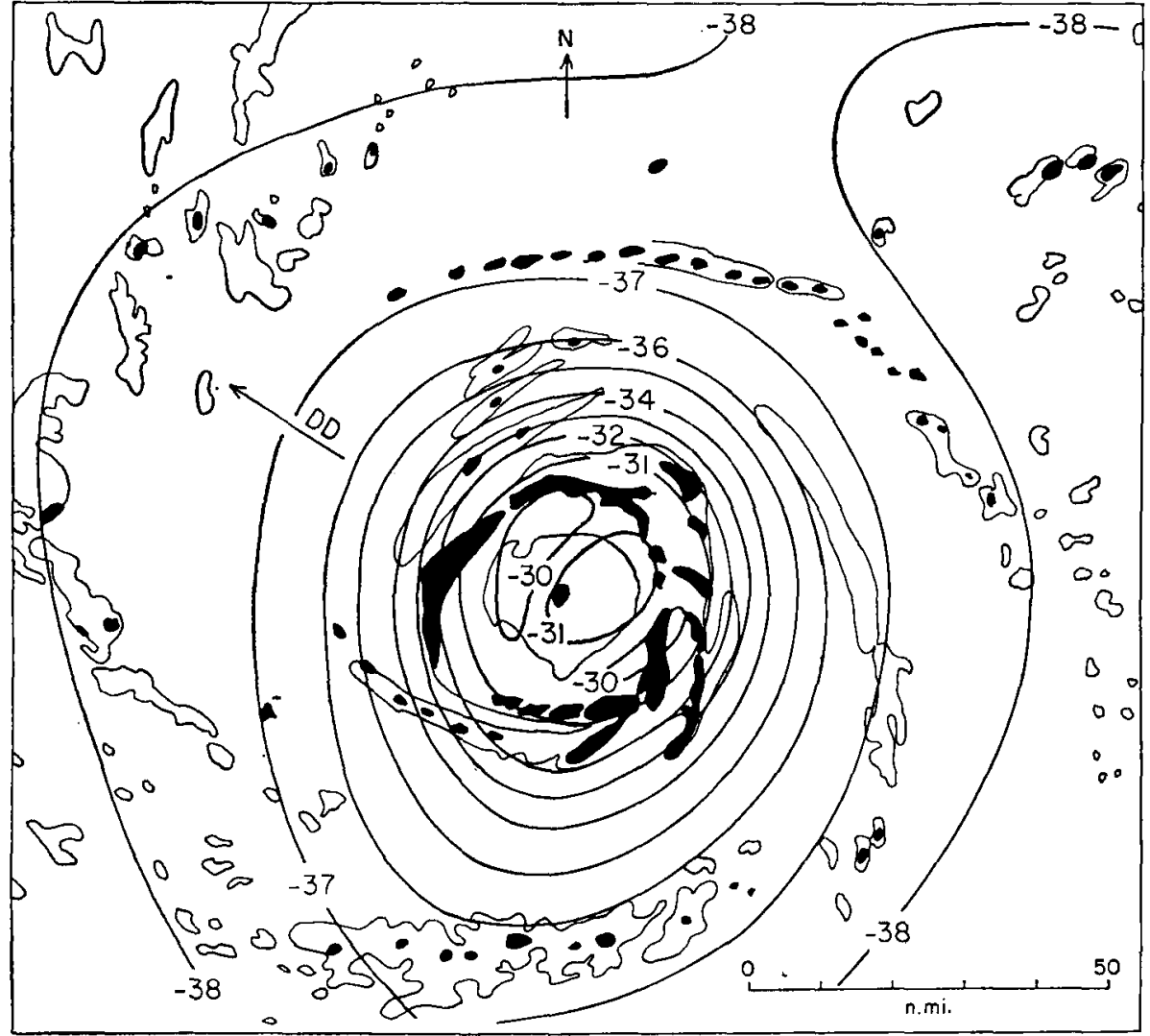

Fig. 5. Temperature (in degrees Celsius) near an altitude of 10,700 meters, as measured by B-47 aircraft in hurricane Helene off the southeastern coast of the United States on 26 September 1958. (Solid areas) Intense radar echoes; (outlined areas) weak radar echoes. [Radar analysis courtesy of William Gray, Colorado State University] give the U.S. Weather Bureau responsibility for a broad program of observations of tropical cyclones. As a result, the National Hurricane Research Project was born, a collaborative effort of the Weather Bureau and the military services.

The achievements of this project cannot be overestimated. Of its manifold activities, the major innovation (for which the first director, Robert H. Simpson, deserves credit) was the outfitting of aircraft for taking measurements across the interior of hurricanes. Before this, because of the difficulties of releasing balloons in high winds, virtually no upper-air data on the interior of hurricanes had been obtained.

In an uncontrolled laboratory such as the atmosphere, the decision as to when it is worth while to employ one's resources and launch a full investigative effort is a matter of guesswork. Since, in research, the answer is never known in advance, the "best guess" sometimes is a poor one. About 20 August 1958 a weak wave disturbance in the trade winds crossed the Lesser and then the Greater Antilles, moving slowly westward. On the morning of 23 August (Fig. 1), a Saturday, this disturbance, as seen from Hurricane Project headquarters, then in Palm Beach, Florida, did not look as though it would be a rewarding object for weekend study. Accordingly, the scientific staff-to a considerable extent at my instigation, - sailed off on a jungle cruise. Upon our return late that day it was only too clear that the disturbance, arriving over the eastern Bahamas, was showing signs of intensification and should be investigated at once. But the aircraft crews and supporting personnel had been dismissed for the weekend, and it was only at sunrise on Monday, 25 August, that the first mission, headed eastward, took off for the storm.

From the start it was evident that something unusual was going on. East of Florida the plane crossed a broad calm area without clouds, such as is often found on the outside of a hurricane. Then the white-caps began picking up from the north, and long rows of low clouds, oriented northsouth, came into view-an unfailing sign of a major disturbance. At the center, the winds were just crossing the threshold of hurricane velocity in a small area east of the forming eye.

Three aircraft explored the storm Daisy on that day. A typical track, completed by one of the planes, is in 
the form of a cloverleaf (Fig. 7). This is a very efficient flight pattern for establishing the major features of a storm. In Fig. 8 we see the wind distribution averaged around the six legs of the flight pattern-that is, the symmetrical part of the wind profile. Maximum speed at a radius of less than 20 kilometers ( 10 miles) from the center already had been established. Hurricanes are individualistic. Daisy retained the narrow core even 2 days later, when the symmetrical profile attained 180 kilometers per hour (100 knots) and when velocities in the range of 200 to 220 kilometers per hour ( 110 to 120 knots) were measured east of the cente (Fig. 8 ).

The stury was quite different a month later when a disturbance, known as hurricane Helene, advanced northwestward in the Atlantic toward the Georgia-Carolina coast. In this case a definite surface center, slowly growing, could be identified for several days before hurricane speeds developed. This storm was successfully intercepted as

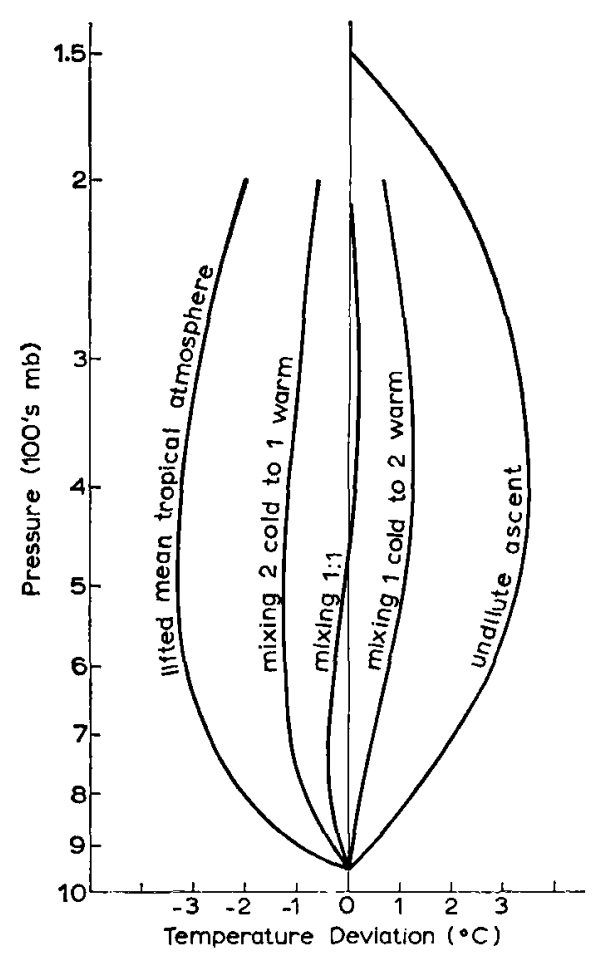

Fig. 6. Pressure on a logarithmic scale (proportional to height) plotted against deviation of temperature from that of the mean summer atmosphere for the Caribbean (see Fig. 3). (Curve at far right) The undilute ascent of surface air as shown in Fig. 3; (curve at far left) temperature distribution resulting from lifting of the mean tropical atmosphere by a distance equivalent to a change in pressure of 50 mill bars; (middle curves) combinations of the curves at far right and left, with the mixing rates indicated. [After Riehl (5)] soon as it came within range of the research aircraft. The velocity profile on 24 September (Fig. 9) is inverse in slope to that found in the first penetration of Daisy. Yet the ultimate hurricane wind profiles are very similar in the two cases, both in slope and in maximum speed; however the eye of Helene remained large compared with that of Daisy.

The U.S. Navy and Air Force have operated hurricane and typhoon reconnaissance missions since the days of World War II. They have long observed that some storms develop from the inside out and others from the outside in. Daisy and Helene exemplify these two modes of growth. But still another case must be cited. Early on 21 September 1957 a low-pressure center began to develop several hundred kilometers southwest of Bermuda. Although this center was only barely within reach of the research aircraft in Florida, the Hurricane Project moved very swiftly, and a plane departed within a few hours after formation of the disturbance. Arriving in the area of the center at nightfall, we were treated to a spectacular display of lightning. Fortunately the modern flying laboratory, with its sensors, does not depend on daylight, and investigation of the core proceeded. Heavy rains and highest winds were situated east of the center. There, the wind profile (Fig. 10) gave every indication of an incipient hurricane.

Tropical storm Frieda was covered on three successive days, especially on 23 September when it was closest to Florida. An Air Force B-47 flying at 10,700 meters $(35,000 \mathrm{ft})$ found typical hurricane structure: clockwise circulation at this height on top of counterclockwise flow at low levels, plus outflow from a warm central region. Everything seemed set for a hurricane, yet nothing happened. Looking down from the aircraft we could see ships peacefully pursuing their course across a broad central area of light winds, with only an upper overcast present. Heavy precipitation, as usual in the form of narrow elongated bands, was concentrated far to the east of the center. There, winds attained gale strength (Fig. 10). But the maximum wind, which had a lower speed than 2 days earlier, was well over 150 kilometers from the core. Inside the disturbance the winds had dropped distinctly from those on 21 September. All in all, it was a bad day for hurricane theories.

\section{Research Trends}

We may summarize the present position as follows. Hurricane formation is rare. The contrasts in air masses normally found in middle latitudes do not exist in the tropics prior to the onset of a hurricane. An atmosphere warmer than normal must be generated from condensation heating in a limited area; this is not readily accomplished. Frequently the air is colder, not warmer, in a large rain area than it is in the surrounding atmosphere. Even when a warm core is formed, with

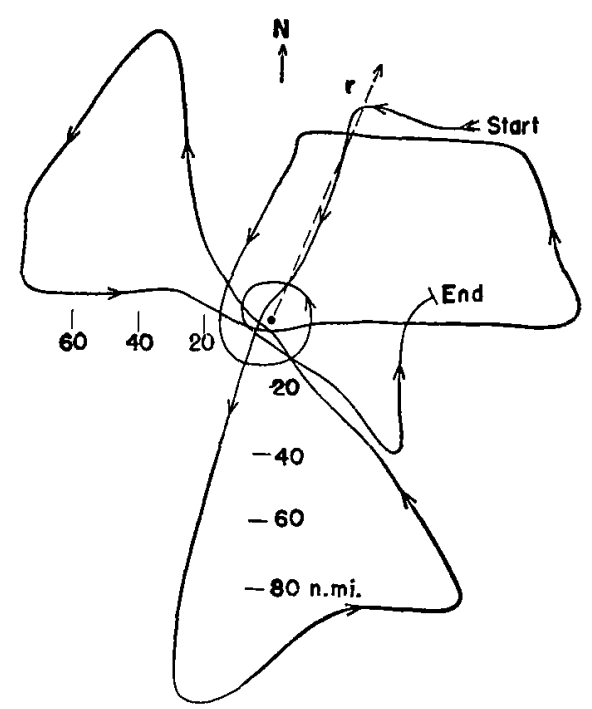

Fig. 7. Typical flight pattern for reconnaissance planes in hurricane Daisy on 25 August 1958 off the coast of Florida, at an altitude of about 1500 meters. Movement of the hurricane center during execution of the flight pattern was taken into account during the flight; this movement has been eliminated from the diagram.

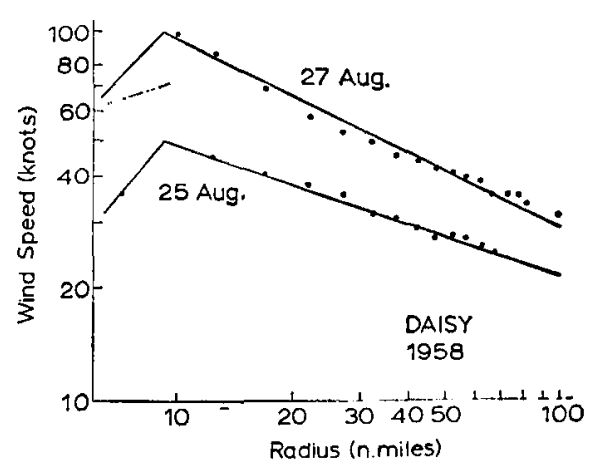

Fig. 8. Profile of wind speed plotted against radius for hurricane Darsy on 25 August 1958 at an altitude of 1500 meters and on 27 August 1958 at an altitude of 4000 meters. The profiles give the wina distribution obtained by averaging the data from six or more flight legs such as those represented in Fig. 7. Since vertical wind shear is small below 6000 meters, the two profiles are comparable in spite of the difference in altitude. 

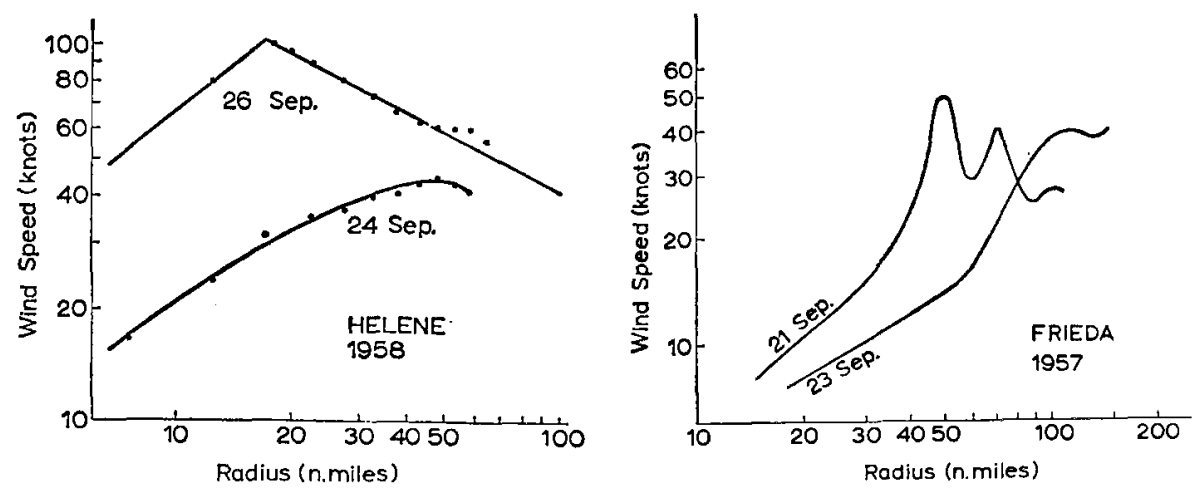

Fig. 9 (left). Profile of wind speed plotted against radius for hurricane Helene on 24 and 26 September 1958. The altitude range for the flights was the same as for Fig. 8. Fig. 10 (right). Profile of wind speed plotted against radius east of center for tropical storm Frieda, southeast of Bermuda, on 21 and 23 September 1957. The flight altitude was 450 meters-that is, near cloud base-on both days.

counterclockwise circulation near the ground changing to clockwise circulation at high levels, hurricane generation need not follow. When it does occur, the wind field may develop in several very different ways, though ultimately a standard type of wind structure emerges. Further, formation of a hurricane may be a gradual process, consuming days, or it may occur swiftly, in 6 to 12 hours.

In spite of the fact that the mature hurricane is the nearest thing to a simple heat engine found in the atmosphere, we must conclude that the "simple heat engine" is not produced in a simple way, and that there are some elusive constraints.

Returning to Fig. 6, we must specify some mechanism for the shift from the left to the right side of the diagram. Following one type of suggestion, we should look for situations in which the decrease in temperature with height is greater than it is for the mean tropical atmosphere. The idea is that,

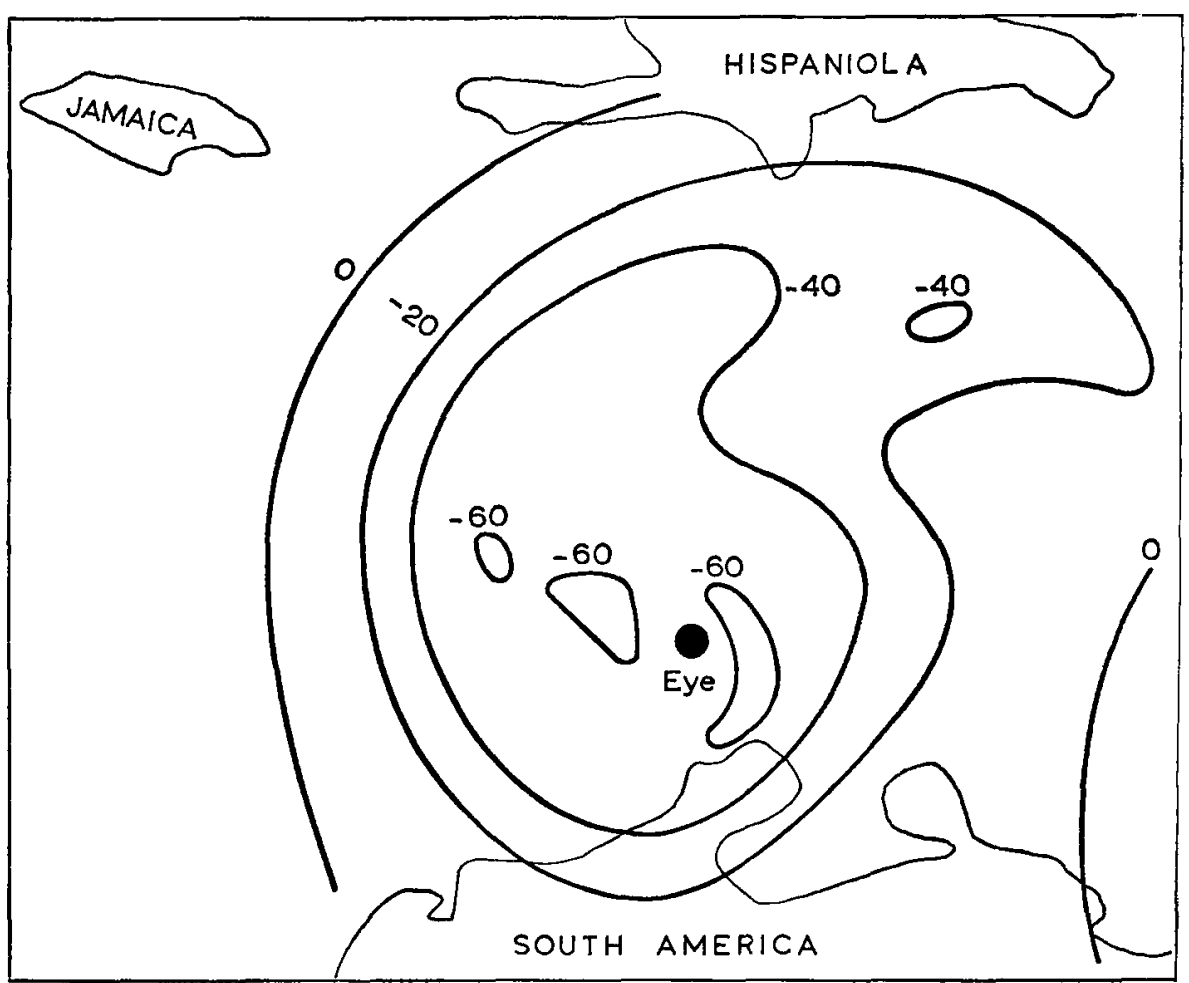

Fig. 11. Simplified diagram of the distribution of effective radiation temperature (in degrees Celsius) as seen by the Tiros III satellite during its pass over hurricane Anna in the Caribbean on 21 July 1961. The low temperatures suggest that a very high cloud mass located at altitudes where these temperatures prevailed (see Fig. 3) was the main radiating surface. [Courtesy T. Fujita, University of Chicago] given similar surface conditions, more active overturning and upward transport of air mass in buoyant towers would take place. In this suggestion the fact that the tropical atmosphere is created by a repeated mixing of cumulus clouds (see 4) is overlooked. An unusually steep temperature lapse rate is coupled with unusually dry conditions. Cloud towers rising in such an environment will erode through mixing with the dry surroundings. Hence, this case is unfavorable for the creation of warm-core rain areas.

I am also skeptical of attempts to link hurricane development with local "hot spots" in the ocean-that is, small water areas with temperature 0.5 to $1^{\circ} \mathrm{C}$ above the temperature characteristic of a whole region. The thought is that, given rapid heat exchange between ocean and air, the undilute-ascent curve of Fig. 6 would be shifted somewhat to the right.

It is true that hurricane formation is concentrated in the broad ocean areas and during seasons when water temperatures are highest. Thus, the cases cited in this article occurred in August and September in the western tropical Atlantic. But there is much evidence that denies a more detailed linkage; a random relationship between the development of hurricanes and small local temperature anomalies is indicated.

More interesting is the possibility that there is considerable suppression of long-wave radiation from potential hurricane areas. A shield of high clouds covers the mature hurricane. Should this thick, solid "canopy" be very cold, long-wave radiation would be substantially below the level for the atmosphere above the tropics at large and below that for disturbed areas with only partial high cloud cover.

In a spectacular analysis of radiation data from Tiros III, T. Fujita has demonstrated lowest effective radiation temperatures near $-70^{\circ} \mathrm{C}$ for hurricane Anna on 21 July 1961 (Fig. 11). By "effective radiation temperature" is meant the black-body temperature corresponding to the observed flux of radiation heat. At $-70^{\circ} \mathrm{C}$ this flux is 0.14 calorie per square centimeter per minute, as compared with a normal flux of about 0.35 calorie per square centimeter per minute for the tropics at an effective radiation temperature near $-17^{\circ} \mathrm{C}$. The difference is very large. If it should occur in situations 

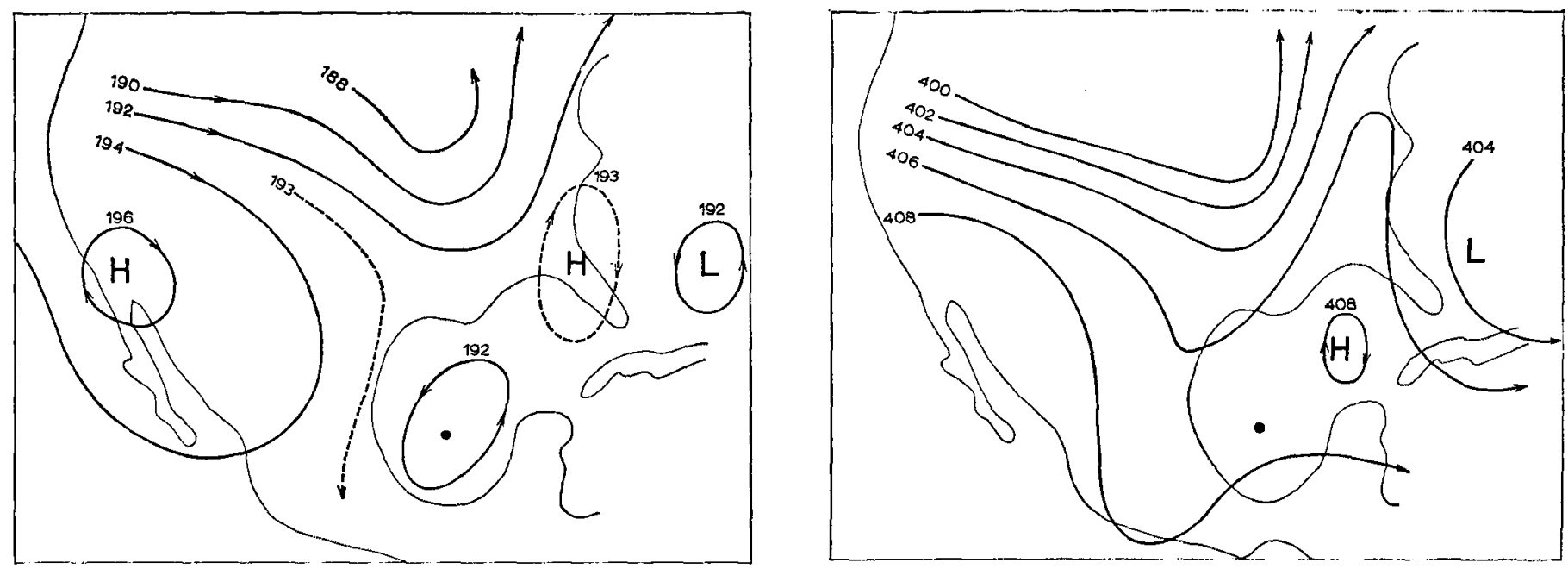

Fig. 12. Contours of (left) 500-millibar and (right) 200-millibar surfaces (altitudes are in hundreds of feet). with arrows marking the direction of flow, for the period just preceding the formation of hurricane Audrey (solid dot) in the Gulf of Mexico on 25 June 1957, 0000 Greenwich Mean Time.

suitable for formation of a hurricane the air under the canopy would warm up by about $1^{\circ} \mathrm{C}$ in 24 hours, relative to the outside air, as a result of this one effect. This would be important; it may be decisive. Studies on this intriguing point should, and undoubtedly will, go forward. Yet we must be conservative in our expectations. From extensive observation, from below, of the high clouds of the storm Frieda, which occurred before the launching of Sputnik, there is reason to suspect that a satellite would have seen a hurricane-type canopy on 23 September 1957.

The main contention in research on hurricane formation revolves around the question of whether "internal" factors determine the development of hurricanes or whether we should study external forcing mechanisms. Members of the "internal" school count it in their favor that Daisy and Helene took such different routes in their development, with rather similar results. Various dynamical constraints can affect the initial structure of the hightropospheric flow at altitudes of about 12,000 meters $(40,000 \mathrm{ft})$ over an incipient disturbance. Some constraints are favorable for the lateral eviction of air mass that has risen in cumulus towers. This lateral eviction would accelerate the circulation sketched in Fig. 2 , left, and shift the temperature of the mixed atmosphere from colder to warmer, as represented in the middle curves of Fig. 6, from left to right.

In spite of these attractive possibilities, evidence has accumulated over the years which suggests that develop- ing storms respond to influences from higher latitudes-that, in particular, intensification is likely to occur when a trough in the mid-latitude westerlies passes the longitude of a potential hurricane (3). Figure 12 shows the critical moment for the beginning of hurricane Audrey in 1957, which became a severe hurricane at landfall in western Louisiana. The physical con-

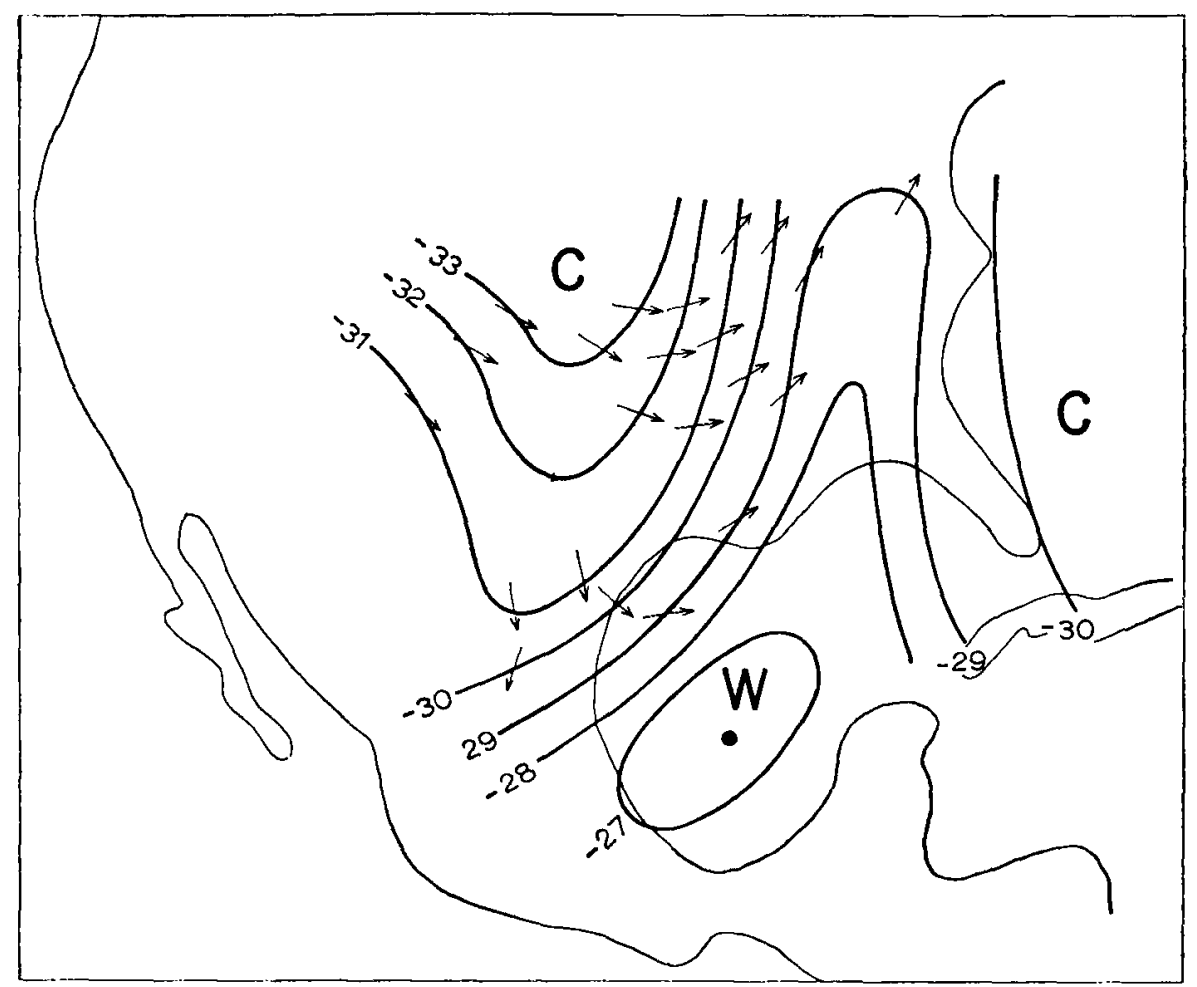

Fig. 13. Mean temperatures (in degrees Celsius) for the layer of atmosphere between heights equivalent to 500 and 200 millibars on 25 June 1957. The arrows indicate the direction of thermal advection by mean flow of the layer. Where arrows cross from cold toward warm air, an advance of cold air is indicated. (Solid dot) Hurricane Audrey. nection may lie in the fact that a portion of the temperature gradient in middle latitudes is swept against the edge of the tropical depression. If this is significant, we would postulate external cooling, not internal warming, as the mechanism that initiates acceleration of the circulation shown in Fig. 2.

This hypothesis deviates from established thought on hurricane develop- 
ment. In its favor are statistical analyses showing that a net low-level indraft into a tropical disturbance must precede intensification at radii from 300 to 800 kilometers ( 200 to 500 miles) from the center of the disturbance. These radii are much too large to be related to internal structure. Furthermore, the cold air arriving aloft at the Gulf Coast on 25 June 1957 and in similar situations was sinking. This may be inferred from the horizontal temperature advection-that is, replacement of warm by cold air-for the layer 500 to 200 millibars (Fig. 13). Strong cold-air advection in the layer prevailed along most of the Gulf Coast. Since actual temperature changes with time were small, compression heating during descent must have compensated for the importation of cold air. As a result, a release of gravitational potential energy, which may have provided the starting energy for the hurricane, took place. Such a release would also accelerate the circulation in the vertical plane (Fig. 2, left). Since the whole arrangement of Figs. 12 and 13 is rare, there would be only a few days in each hurricane season when formation from external forcing was a possibility.

If this chain of events should prove to be relevant, the difference in cyclone-producing mechanisms inside and outside the tropics would be far smaller than is generally assumed to be the case. But we cannot be certain. Since we lack neither an array of competing theories nor batteries of excellent computers, rapidity of progress in this challenging field really depends on the capability of the National Hurricane Research Project to furnish the required upper-air surveillance inside and on the periphery of areas with hurricane potential.

\section{Hurricane Modification}

Irrespective of the possible role of external energy sources in initiating the formation of a hurricane, the mature storm is maintained largely by condensation heating. Rapid pickup of sensible heat and water vapor from the ocean increases the heat content of the inflowing air mass, once a highwind regime has been established. Such heating within the hurricane envelope produces the high temperatures of Fig. 3 , which cannot be derived from normal trade-wind air.

For centuries hurricanes have been classed among the most violent manifestations of weather. Various schemes, not worth listing, have been advocated

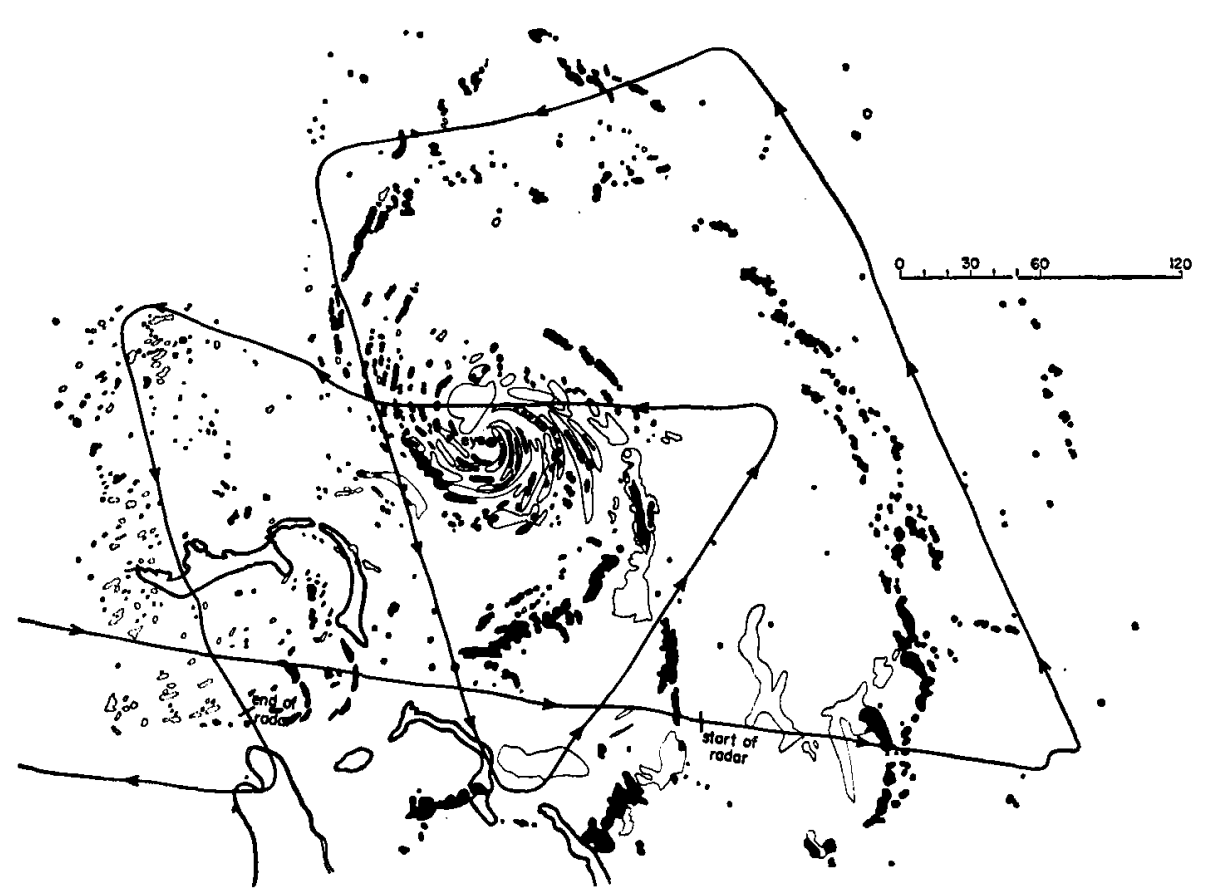

Fig. 14. Distribution of radar echoes (the solid areas are intense echoes; outlined areas are of lesser intensity) for hurricane Daisy on 25 August 1958, 1800-2300 Greenwich Civil Time. (See Fig. 8 for the wind profile.) The flight path of the B-47 aircraft at 10,500 meters is shown. Scale is indicated in nautical miles. [Courtesy William Gray, Colorado State University]

for destroying them. In 1946, however, a famous experiment in cloud modification was undertaken by V. J. Schaefer and I. Langmuir (8). By seeding stratus clouds consisting of water particles at temperatures well below freezing -that is, "supercooled" drops-with dry ice from a small airplane, they were able to demonstrate that the water cloud was converted to ice crystals, which fell out and left a hole in the cloud. Subsequently a vast amount of research on cloud modification unfolded and is continuing. A few minor experiments were even performed in hurricanes, but the outcome was indifferent or controversial. Yet modifying the hurricane remains an attractive possibility. The hurricane is, after all. the only major atmospheric disturbance mainly running on the condensationprecipitation process, which, as Schaefer's experiment demonstrated, is susceptible to man's interference.

At this point we must ask ourselves rather soberly what man can possibly hope to accomplish in combat with the hurricane, with its enormous forces and energy. In large, mature hurricanes the amount of kinetic energy produced is $10^{11}$ to $10^{12}$ kilowatt-hours per day (9); this is 100 to 300 times the electric power production of the United States. The efficiency of the hurricane engine in converting latent heat to kinetic energy is low, as is usual in atmospheric energy conversions; it is of the order of 1 to 3 percent. In the face of such magnitudes, it is reasonable for us to have some doubts about the feasibility of ventures for modifying hurricanes.

Yet the observations of the Hurricane Project have produced some evidence that is of much interest in this connection. Most important is the fact that the principal ascent of mass and moisture around the eye of a hurricane is not uniformly spread over the ring in which winds are high. As Fig. 5 shows, the area for which radar echo is intense may be quite small. J. S. Malkus (10) made a detailed study of the vertical transport of mass and moisture in hurricane Daisy, on the basis of cloud photographs and a radar analysis made by William Gray (Fig. 14). She concluded that intense radar echoes were received from only 6 percent of the area within an 80kilometer radius from the wall of the eye; the percentage for the area farther out was lower. This is a rather remarkable finding, which suggests that, given 
adequate technology, attempts at modification can be restricted to a very small part of the hurricane volume.

R. H. Simpson, R. C. Gentry, N. E. LaSeur, and others, who have spent a considerable number of hours flying around in the eyes of hurricanes, have all reported that the central parts of the hurricane are in a continual state of transformation and that the surface barometric pressure in the center may fluctuate appreciably in the course of several hours. It might be possible to manipulate this internal turbulence to advantage. While the general symmetric part of the circulation (Figs. 8 and 9) is essentially stable with respect to disrupting influences of the microstructure, the overall intensity of the hurricane does not remain constant over a 24-hour period. The intensities and paths of hurricanes are very sensitive even to small influences from weather patterns outside the tropics and on occasion hurricanes have dissipated over open water. There are also odd oscillations, ascribed to internal forces within the circulation in storm tracks. Notable in recent years was the erratic behavior of hurricane Carla in the Gulf of Mexico (see Fig. 15).

Under these circumstances it does not appear to be completely beyond hope that at least some reduction of the high wind-specds in the small central area can be achieved. Two procedures for modifying hurricanes have been suggested, starting with the premise that ice nuclei are necessary for the conversion of water drops to, ice crystals, at least above certain very low temperature thresholds: that such nuclei are rare or are washed out; and that introduction of such nuclei can modify the condensation-precipitation cycle.

One of these hypotheses (mainly attributable to V. J. Schaefer) is based on recognition of the fact that the release of latent heat through condensation will not warm the interior of the hurricane unless the condensate falls out as rain. For precipitation to occur. many small water drops must coalesce to produce raindrops with diameters from less than 1 to over 5 millimeters. A tall cloud with high liquid-water content over great depth evidently improves the chances that such coalescence will occur. If nuclei capable of converting water to ice at temperatures slightly below freezing could be introduced in sufficient number, the depth

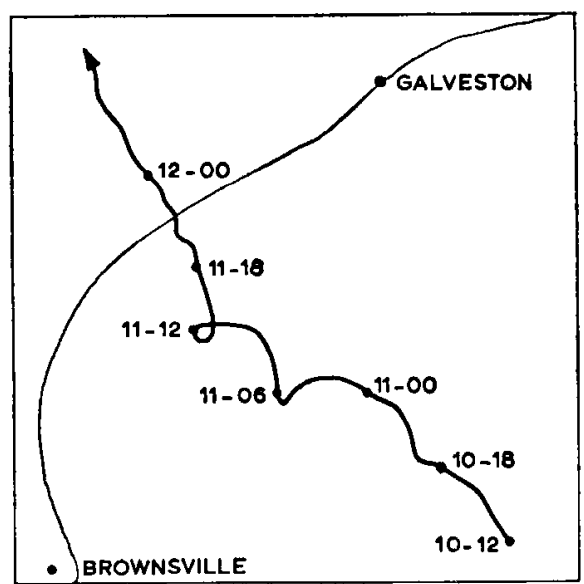

Fig. 15. Track of hurricane Carla in the Gulf of Mexico from 10 to 12 September 1961. The dots mark 6-hourly positions, beginning at 1200 Greenwich Mean Time on 10 September. Irregularities of the track, as observed from land-based radar sets, may be accepted as realistic.

of cloud with substantial liquid-water content might be reduced by 50 percent. Many small ice crystals would form. These would not fall out rapidly but would tend to evaporate by mixing into cloud-free air at the edges of the massive cloud bands. In this way the difference in temperature between the interior of the hurricane and the surrounding parts of the storm would be reduced. A decrease in wind intensity might follow-that is, if no factor of importance has been omitted in this chain of reasoning.

According to the alternative hypothesis, proposed by R. H. Simpson et al. (II), massive injection of ice nuclei, in depth, into the cloud that contains

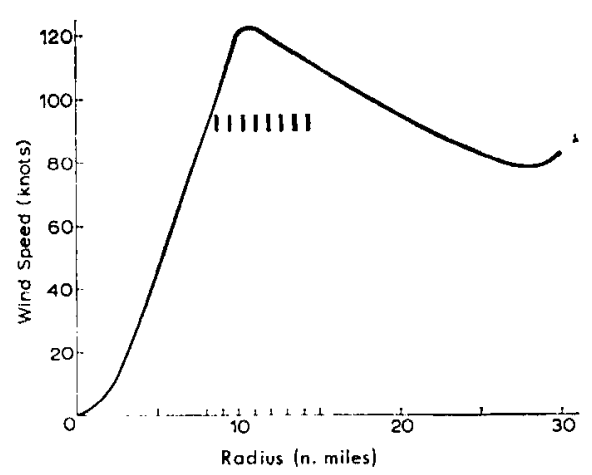

Fig. 16. Profile of wind speed at $2150 \mathrm{~m}$ plotted against the radius of hurricane Esther on 16 September 1961, when the hurricane was near latitude $25^{\circ} \mathrm{N}$, north of Puerto Rico. This profile was taken through the cloud wall north of the westward-moving center, where a Navy A-3D aircraft. flying at an altitude of about 13.700 meters, dropped eight generators, seeding the storm in depth with silver iodide crystals at the locations indicated. supercooled water will produce an additional heat source from release of latent heat of fusion. If this heat source is "applied" at some little distance from the storm center, an asymmetric element that may be capable of rearranging the hurricane energy is introduced into the distribution of heating.

After a device for seeding clouds in great depth had been developed by the U.S. Naval Laboratory at China Lake, California, the U.S. Weather Bureau and the U.S. Navy, with support from the National Science Foundation, organized a joint venture to try to modify hurricanes by this means. Before August 1963, only a single set of experiments had been carried out, on 16 and 17 September 1961, in hurricane Esther, at about latitude $25^{\circ} \mathrm{N}$, north of Puerto Rico. Since the storm was moving toward the west-northwest, the strongest wind sector and the heaviest cloud mass, with thunderstorms, were situated north-northeast from the eye. Figure 16 shows the wind profile of this sector and the points at which a Navy A3-D aircraft flying near the cloud tops at an altitude close to 13.700 meters dropped generators for seeding the clouds with silver iodide crystals. These generators were timed to burn down to heights of 6500 meters.

Observers in a large number of airplanes at different altitudes watched the performance and monitored the storm for some hours before and after the flight of the seeding airplane. Most interesting is the radar evidence. There were no changes in the echoes from radar emitting electromagnetic waves of 3-centimeter wavelength. A profound change occurred in the observations of radar emitting energy at a wavelength of 10 centimeters-a wavelength which is not reflected by very small water drops and by ice crystals. Reflection of energy at this wavelength disappeared from the general area of the seeding flight downstream over a 160-degree sector. An hour after the operation the original picture had been restored.

This different course of radar observations suggests that the major portion of the reflecting water mass was frozen. This is an attractive hypothesis, but meteorology is not so simple. The change in the 10-centimeter radar observations did not occur until 20 minutes after the silver iodide generators had been dropped. There is no reason to expect a lag of such dura- 
tion, especially when the seeding is in depth; the reaction should have set in almost at once. Worse yet, since the winds were near 180 kilometers per hour, all the material should have traveled a great distance in 20 minutes. At the 15-kilometer radius, for instance, the seeded air should have moved about halfway around the storm, since, in the southwest sector, the winds did not exceed 150 kilometers per hour ( 80 knots). Therefore there is no obvious reason for connecting the radar fadeout with the seeding. Yet the transformation in the observations of the 10-centimeter radar was spectacular, and veteran observers of radar in hurricanes have stated that they have not found such marked changes on other occasions.

Changes in the wind field were small and probably within the range of normally occurring microfluctuations, but this finding is without relevance, since only one set of generators was dropped. The atmosphere is a rather inert medium, and large-scale circulations respond slowly to impressed changes. Enormous instantaneous infusions of energy, such as are supplied by hydrogen bombs, have not been observed to affect broadscale flow features of the troposphere. The energy disperses rapidly, and only a traveling pressure wave can be followed. In considering ways to make an impact on a weather system as large as a hurricane, where the earth's rotation is involved, one must think in terms of continuing operations, with a minimum duration of 12 hours.

In summary, the whole experinent leaves us without obvious concrete results but with more curiosity than ever, and with some feeling of encouragement. It is safe to predict that future experiments will be watched by the meteorological profession, and by the public, with more than casual interest (I2).

\section{References and Notes}

1. V. Bjerknes et al.. Physikalische Hydrodynamik (Springer, Berlin, 1933).

2. G. E. Dunn, Monthly Weather Rev, 68, 303 (1940).

3. H. Riehl, Tropical Mcteorology (McGrawHill, New York, 1954).

4. - Science 135, 13 (1962)

5. $\longrightarrow$ Univ. Chicago Misc. Repts. No. 24 (1948).

6. M. Yanai, J. Meteorol. Japan, 39, 187 (1961)

7. The practice of assigning girls' names to hurricanes started during World War II as an outgrowth of G. R. Stewart's Storm (Random House, New York, 1941). After 20 years, a change might be welcomed.

8. V. J. Schaefer, in Compendium of Meteor ology, T. F. Malone, Ed. (Am. Meteorol. Soc., Boston, 1951).

9. E. Palmén and H. Riehl, J. Meteorol. 14, 150 (1957)

10. J. S. Malkus et al., Tellus 13, 8 (1961).

11. R. H. Simpson, M. R. Ahrens, R. D Decker, "National Hurricane Research Project Report No. 60," U.S. Weather Bureau Publ. (1963).

12. A second experiment was performed on 23 August 1963 